\title{
ТРЕУГОЛЬНИК ЗНАНИЙ: ПРОБЛЕМА КАПИТАЛИЗАЦИИ УЧЕБНОГО ПРОЦЕССА
}

\author{
Витулёва Е.С. ${ }^{1}$, Байпакбаева С.T. ${ }^{2}$ \\ (1) доктрант PhD, Алматинский университет энергетики и связи, г. Алматы, Республика Казахстан, \\ Lizavita@list.ru \\ (2) Институт информаџионных и вычислительных технологий, г. Алматы, Республика Казахстан, \\ saltanat.baipakbayeva@gmail.com
}

Показано, что существует ещче одно направление деятельности, направленной на диверсификацию доходов университетов, связанное с сопряжением учебного процесса с реализацией прогностических методов. Соответствующие прогностические сервисы реализуются через выполнение учебных заданий обучающимися в рамках таких дисциплин как «Теория и практика инновационной деятельности». Формой реализации учебных заданий являются ролевые игры, моделирующие рынок инновационных продуктов.

Ключевые слова: треугольник знаний; коммеричилизация; принципь Гумбольдта; финансирование университетов; продвижение инноваций.

\section{KNOWLEDGE TRIANGLE: THE PROBLEM OF CAPITALIZATION OF THE EDUCATIONAL PROCESS}

\section{Vitulyova E.S., Baipakbayeva S.T.}

It is shown that there is another area of activity aimed at diversifying the incomes of universities related to the conjugation of the educational process with the implementation of prognostic methods. Relevant forecasting services are implemented through the implementation of educational tasks by students in such disciplines as "Theory and practice of innovation." The form of implementation of educational tasks are role-playing games that simulate the market for innovative products.

Keywords: knowledge triangle; commercialization; Humboldt principles; university financing; innovation promotion; sales forecasting.

\section{1. Введение}

В настоящее время в постсоветской педагогической литературе все чаще обсуждается концепция треугольника знаний $[1,2]$, под которым понимается как триединство собственно образования, научной и инновационной деятельности. Понятие «треугольник знаний» отражает взаимодействие между образованием, научными исследованиями и инновациями, в совокупности являющимися главной движущей силой экономики, основанной на знаниях [1] фиг.1. 


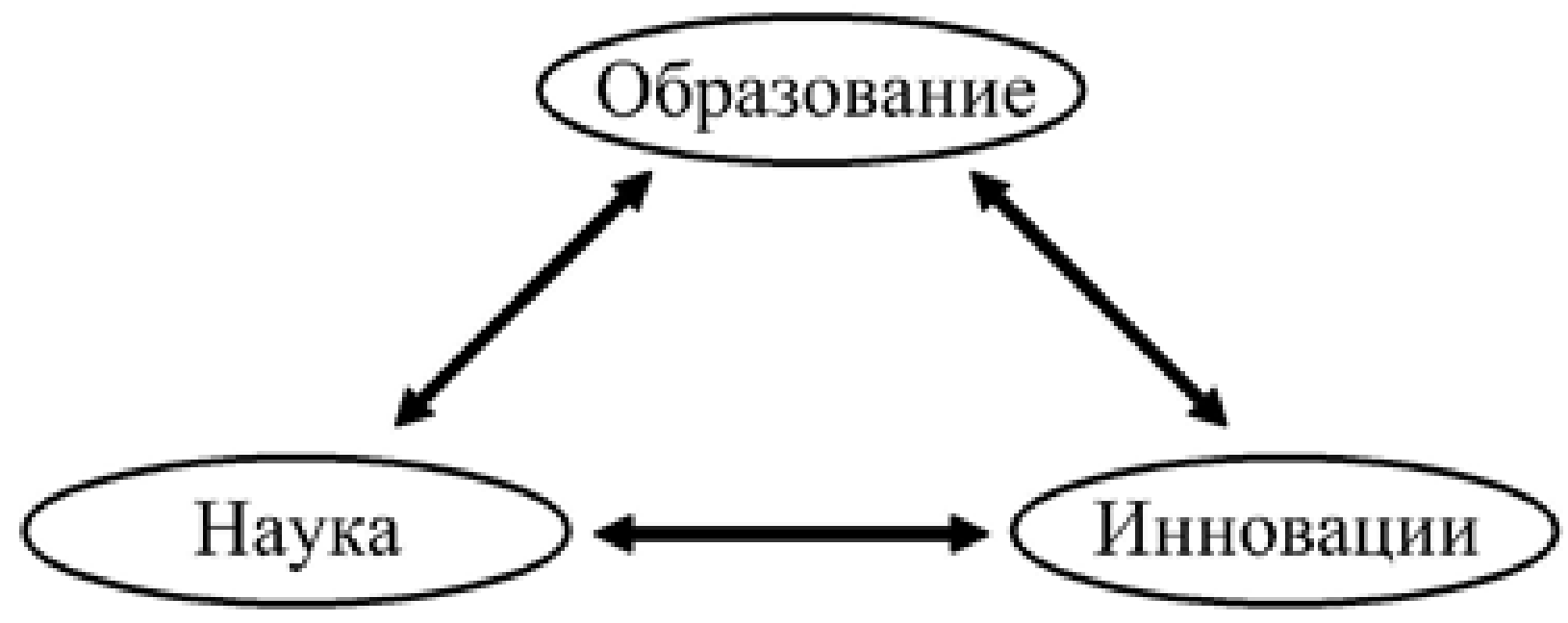

Фиг. 1. Простейшая схема треугольника знаний

В работе [1] также подчеркивается, что модель университета, созданная в начале XIX века благодаря реформаторской деятельности Вильгельма фон Гумбольдта [4], и ставшая доминирующей к концу XIX века, более не может дать ответы на все вызовы, с которыми сталкивается современное общество. В пользу этого вывода можно привести следующие аргументы.

Базовыми принципами фон Гумбольдта являются академические свободы и единство научных исследований и высшего образования [1,4]. Эта модель предполагает, что общество (например, в лице государства) полностью обеспечивает университеты необходимыми ресурсами. Ученые, работающие в университете, пользуясь академическими свободами, генерируют фундаментальные знания, ориентируясь преимущественно на собственные интересы, и доносят знания до студентов в тех объемах и формах, которые полагают целесообразными [1].

Подчеркиваем, что принципы фон Гумбольдта действительно оказались весьма жизнеспособными и результативными. В конечно счете, именно благодаря инициированной им модернизации высшего образования, западноевропейская науки и созданная на еe основе западноевропейская цивилизация обеспечили себе геополитическое доминирование на рубеже XIX и XX веков [6].

\section{2. Концепция треугольника знаний}

Однако принципы фон Гумбольдта в полной мере можно было реализовать только тогда, когда высшее образование было сугубо элитарным [6]. Так, в современных условиях, когда учебная нагрузка преподавателей примерно в 10 раз превышает [7] этот показатель для начала XX века (уже не говоря об уровне оплаты труда), об академических свободах и единстве науки и образования говорить можно разве что только формально - у подавляющего большинства преподавателей университетов на 
это просто не остается времени (особенно, если принять во внимание фактор безудержной бюрократизации учебного процесса).

Такое положение дел во многом обусловлено объективными причинами. К началу XXI века высшее образование стало массовым; в большинстве постсоветских стран студентами являются более половины молодых людей соответствующей возрастной группы. Как следствие, общество уже не может обеспечить университеты ресурсами (включая финансирование преподавателей) на том уровне, который сложился в начале XX века (в период расцвета эпохи Модерн).

Не будет большим преувеличением сказать, что постсоветская высшая школа до сих пор продолжает искать ответ на вызов массовости. Авторы [1] выразились на этот счет следующим образом: «диверсификация источников дохода университетов, в рамках которой снижается доля государственного финансирования в бюджете университетов и увеличиваются их доходы от трансфера знаний, имеет ряд не всегда удобных для университетов следствий». За этой взвешенной и корректной формулировкой стоит очень многое: в настоящее время со всей остротой стоит вопрос о капитализации всех форм деятельности университетов; упрощая, деньги они вынуждены зарабатывать сами.

Именно это является одной из причин, заставляющих ставить вопрос о треугольнике знаний, точнее о необходимости существенной модернизации принципов фон Гумбольдта. Впрочем, следует отметить, что этому есть и другие причины [9]: необходимость включения инновационной деятельности в учебный процесс на систематической основе диктуется также кризисными явлениями в современной науке, рассматриваемой как социальная институция [6], что в совокупности заставляет говорить о необходимости модернизации базовых парадигм науки и высшего образования как таковых [11,12].

Столь существенная модернизация принципов фон Гумбольдта не может не сопровождаться не менее серьёзными изменениями в характере деятельности самих университетов, которые де-факто сталкиваются с необходимостью выходить на рынок инновационной продукции, а, следовательно, осваивать такие новые для себя формы деятельности как маркетинг, расчет издержек, ценообразование, учет финансовых и иных рисков и т.п. [1]. Помимо прочего, это означает, что трансформироваться должны организационные формы всей деятельности университетов, в том числе и непосредственно учебный процесс.

В соответствии со сказанным выше, схему треугольника знаний следует дополнить (фиг. 2.). Этот рисунок подчеркивает, что в рамках университета, реализующего концепцию треугольника знаний, должны, в том числе, существовать те 
или иные структурные подразделения (институции), которые обеспечивают соответствующее взаимодействия между «вершинами» треугольника. Для взаимодействия между наукой и образованием такие институции хорошо известны это исследовательские лаборатории, которые являются неотъемлемой частью классического университета, построенного на модели Гумбольдта.

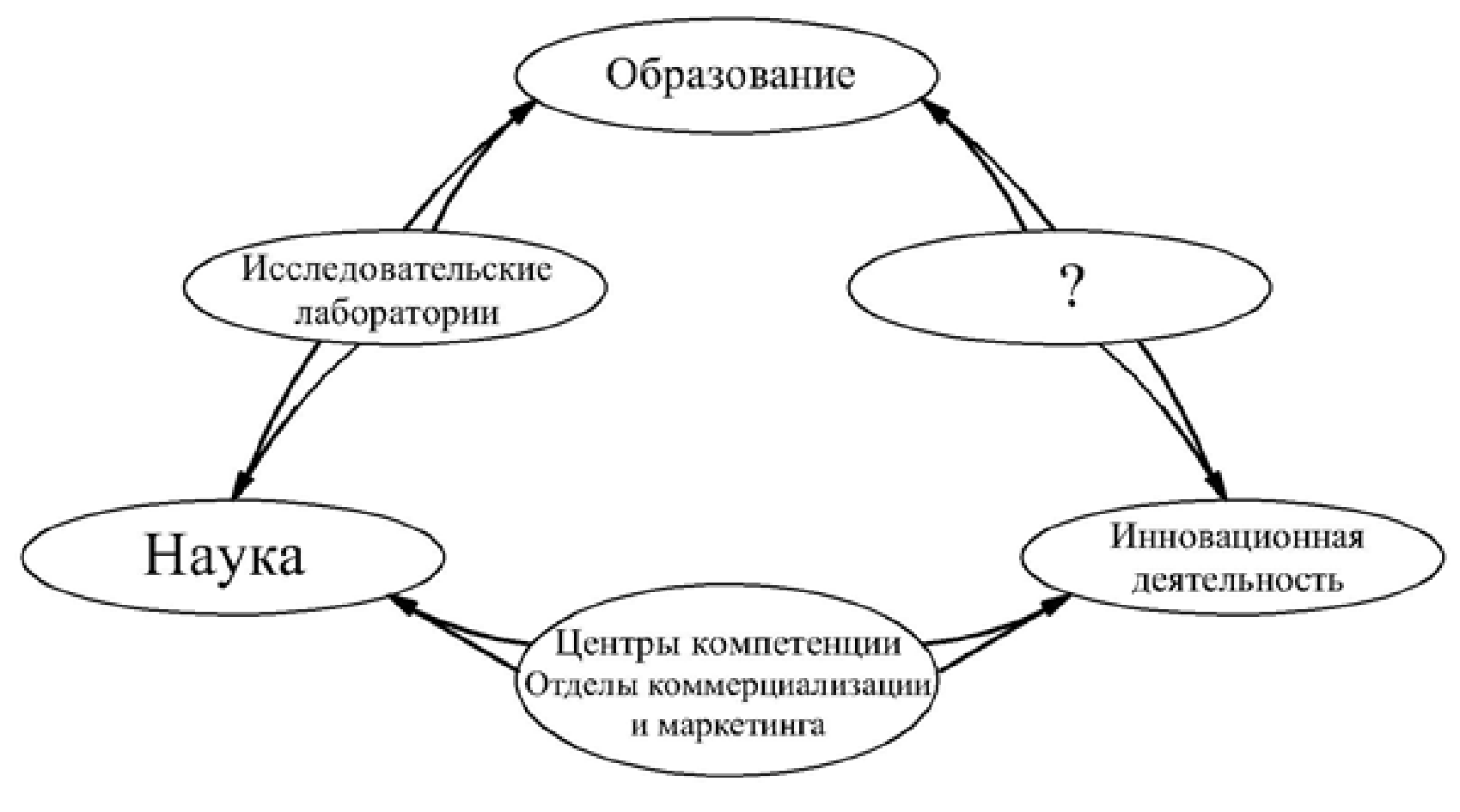

Фиг. 2 - Уточненная схема треугольника знаний

В настоящее время также активно разрабатываются подходы (в том числе, и теоретические [13]) к созданию структурных подразделений, которые обеспечивают собственно трансферт технологий или трансферт знаний. Это - подразделения, которые фактически обеспечивают взаимодействие между наукой и инновационной деятельностью; такого рода подразделения могут создаваться в форме центров компетенции, отделов коммерциализации маркетинга и т.д. Их задача также представляется достаточно прозрачной: несколько упрощая, можно сказать, что именно эти подразделения обеспечивают получение университетами дохода от интеллектуальной (главным образом, научной) деятельности. При этом, однако остаётся открытым вопрос о подразделениях, которые будут поддерживать «третью сторону» треугольника знаний. Этот вопрос нетривиален, и он рассматривается в данной работе.

Оттолкнемся от очевидного факта: уровень коммерциализации научнотехнических разработок (даже при наличии финансирования, выделяемого различными институтами развития, такими как Фонд науки МОН РК) остается весьма 
низким [14]. О том, как в современных условиях сложно генерировать и продвигать на рынок инновации однозначно говорит также и уровень государственно-частного партнерства в данной сфере.

Крайне сложно также ставить вопрос о том, чтобы существенно снизить учебную нагрузку преподавателей, высвобождая время на научные исследования. Это, во всяком случае, на первых этапах приведет не к увеличению, а к снижению финансовой результативности университетов, особенно, если принять во внимание, насколько сложной в современных условиях является генерация и продвижение инноваций на весьма насыщенный рынок, где существует очень жесткая конкуренция.

В качестве возможного выхода из этого положения рассматривается вопрос о вовлечении в проектную/инновационную деятельность студентов и магистрантов [15]. Теоретически, время, которое обучающиеся затрачивают на подготовку выпускных работ и магистерских диссертаций, действительно представляет собой вполне определенный ресурс, который можно было бы использовать именно для генерации инноваций. Однако проектная деятельность обучающихся неизбежно сталкивается с теми же самыми трудностями, в том числе, со сложностью продвижения на рынок любого инновационного продукта.

Следовательно, имеет смысл рассматривать и другие области приложения усилий, нацеленных на получение конечной прибыли университетами.

Обратимся к фиг. 2. Проставленный на нем знак вопроса подчеркивает, что вопрос о прямом сопряжении собственно учебного процесса и инновационной деятельности проработан пока что заведомо недостаточно. Фактически оно осуществляется опосредованно - через два другие «ребра» треугольника знаний.

В то же время основа коммерческой деятельности подавляющего большинства постсоветских университетов непосредственно связана именно с капитализацией самого учебного процесса: значительная часть дохода сформирована платой за обучение (в том числе, на дополнительных курсах, курсах переподготовки и т.д.). Такое положение дел зачастую негативно влияет на качество обучения - университеты вынуждены проявлять максимальную лояльность к обучающимся, чтобы не потерять соответствующие доходы.

\section{3. Проектная деятельность обучающихся}

Следовательно, целесообразно попытаться изыскать другие формы капитализации учебного процесса.

Одним из возможных вариантов здесь является сопряжение учебного процесса и проектной деятельности обучающихся. Такая форма учебной работы предполагает, что 
в качестве практических заданий осуществляется совершенствование учебнометодических материалов магистрантами. В современных условиях такой подход представляется вполне оправданным, так как имеет место устойчивая тенденция, связанная со все более широким применением методов дистанционного обучения, в том числе, видеолекций. Предпосылкой для успешного внедрения обучения на основе видеолекций является постоянная дополнительная поддержка таких лекционных курсов, в том числе, обновление материала (что особенно актуально для бурно развивающихся дисциплин, связанных с информационными и телекоммуникационными технологиями). Подбор первичной информации, создание интерактивного материала и т.д. - это те задачи, которые вполне могут быть решены магистрантами. Такой подход позволяет также совершенствовать материал с точки зрения наглядности и удобства для восприятия за счет коллективной работы обучающихся.

Рассмотренный пример важен, но объем рынка таких информационных продуктов как видеоматериалы для дистанционного обучения является ограниченным, кроме того, здесь легко прогнозировать появление высокого уровня конкуренции между университетами по мере внедрения дистанционных методов обучения.

Следовательно, такого рода деятельность только в небольшой степени позволяет решить вопрос о прямой капитализации учебного процесса. Он, разумеется, должен решаться без ущерба для качества обучения, поэтому имеет смысл снова вернуться к вопросу о модернизации принципов фон Гумбольдта.

Если исходить из предположения, что инновационная деятельность должна стать одной из важнейших компонент высшего образования, то и учебный процесс должен быть модернизирован. Как минимум, в учебные программы магистратуры следует включить соответствующие дисциплины: чтобы обучающие могли успешно заниматься инновациями, их этому, прежде всего, надо научить.

Примером реализации такого подхода является дисциплина «Теория и практика инновационной деятельности», разработанная и внедренная в Алматинском университете энергетики и связи в научно-педагогической магистратуре. Очевидно, что практические занятия по дисциплинам такого рода так или иначе должны быть связаны с инновационной деятельностью. Оптимальным вариантом, конечно, является генерация инновационных идей обучающимися. Однако, как показывает практика, только небольшое число магистрантов способно справится с учебным заданием, предусматривающим хотя бы только формулировку идеи инновационного продукта.

Одно из учебных заданий по данной дисциплине предполагало ответ на вопрос: можете ли вы вообразить себе инновационный продукт, которого сейчас не имеется на 
рынке, но который вы бы хотели приобрести? (Задание, конечно, содержало оговорки, исключающие ответы такого плана как «хочу приобрести вечное здоровье».)

Как показывает практика, подавляющее большинство обучающихся, отвечая на такие вопросы, в лучшем случае, ориентируются на незначительные усовершенствования уже имеющихся на рынке продуктов. Следовательно, имеет смысл рассматривать и задания другого типа, например, связанные с оценкой уже имеющихся инноваций и их совершенствованием/критикой.

Выполнение именно таких заданий является предпосылкой для реализации нетривиальных подходов к коммерциализации учебного процесса. Покажем это.

В современных условиях одними из наиболее перспективных сервисов являются прогностические, причем они являются востребованными как на локальном уровне (продвижение конкретных продуктов, товаров, услуг и т.д.), так и на более высоких (концепция форсайта [16]). Исследование рынка и выработка соответствующих прогнозов является неотъемлемой частью любой маркетинговой стратегии $[17,18]$. С наибольшими сложностями в части выработки прогнозов, очевидно, сталкиваются стартаповские компании, что и заставляет относить их деятельность к высокорисковой. Именно поэтому разработка сервисов, способных формировать адекватные прогнозы для стартапов, является важной задачей не только с точки зрения достижения конкретного коммерческого результата, но и с точки зрения обеспечения долгосрочных интересов постсоветских государств.

Один из наиболее распространенных методов исследования рынка основан на опросах потенциальных потребителей [20,21]. Основными недостатками такого рода методов является высокая стоимость (сопоставимая с затратами на социологические опросы), а также недостаточно высокая мотивация респондентов, или иные факторы, заставляющие их давать недостоверные или искаженные ответы.

Данную проблему решает методика проведения опросов, совмещенная с учебными заданиями. Точнее, такое сопряжение параллельно решает несколько задач:

- обучающиеся изучают текущую обстановку в области реальной инновационной деятельности, причем, компании (в том числе, стартапы) оказываются заинтересованными в том, чтобы предоставить достоверную информацию о своей деятельности;

- обучающиеся приобретают навыки сравнительного анализа инновационной деятельности в различных направлениях, 
- ответы на вопросы становятся намного более взвешенными и продуманными, так как при выполнении учебного задания обучающиеся изучают дополнительные материалы, позволяющие дать наиболее адекватный ответ;

- реализуется прогностический сервис, в том числе, использующий ранее полученную информацию о деятельности реальных компаний;

- потребители получают намного более достоверные данные опросов за счет повышенной мотивации респондентов;

- университет де-факто обеспечивает коммерциализацию непосредственно учебный процесс, получая дополнительный доход от потребителей данной услуги.

Сущность заданий, одновременно служащих и для решения прогностических задач, и для целей обучения, может быть различной. В силлабус, разработанный по упомянутой выше дисциплине «Теория и практика инноваций», входят задания, связанные с оценкой эффективности конкретных инноваций (методом сравнительного анализа), их потенциальной востребованности и т.д. Существенно, что при проведении такого рода оценок обучающие одновременно выступают и в роли экспертов, и в роли потенциальных потребителей инновационного продукта.

Используется также ролевая игра, в которой часть магистрантов выступает в роли «инвесторов», то есть «вкладывает» виртуальные «деньги» в те инновации, которые с точки зрения являются наиболее перспективными, а другая часть - в роли потребителей, «покупающих» данный продукт за условные «деньги». Объем «трат» в обоих случая по условиям ролевой игры остается ограниченным. Схема ролевой игры предложенного типа показана на фиг. 3.

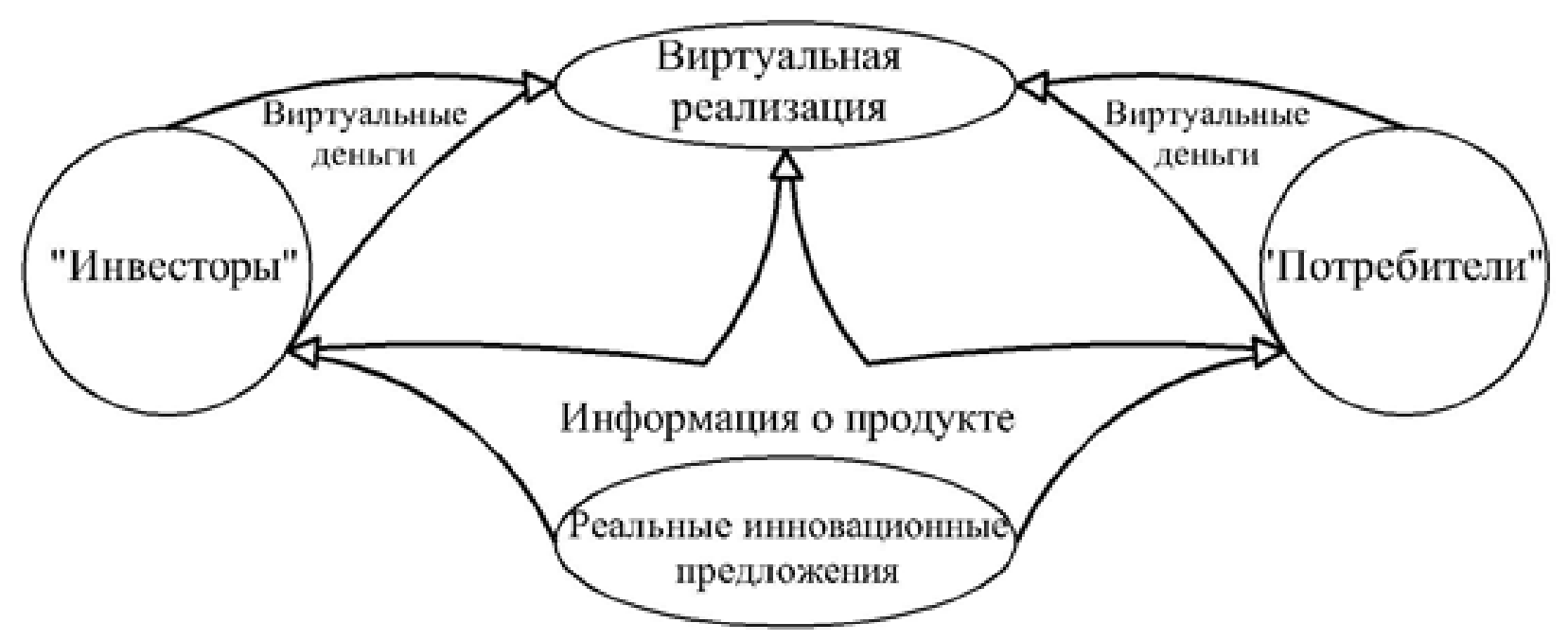

Фиг. 3 - Схема ролевой игры, моделирующей реальный рынок информационных продуктов 
Оценка, выставляемая по результатам игры, определяется тем, насколько мнение, высказанное участником игры (в форме сложения условных «денег»), совпадает с коллективным экспертным мнением, которое может формироваться, в том числе, с привлечением дополнительных экспертных суждений. Последнее, строго говоря, не является обязательным, так как коллективное мнение, формируемое студентами как потенциальными потребителями конкретного продукта не может быть правильным или неправильным; это - не более чем индикатор действительно существующих потребительских предпочтений. Другое дело, что поскольку речь идет о выполнении учебного задания, то здесь возникает стимул для более взвешенной оценки даже на уровне собственных предпочтений.

Можно заметить, что данная ролевая игра в определенной степени моделирует реальный рынок инновационных продуктов, что позволяет говорить о повышении точности информации по сравнению с традиционными опросами.

\section{Заключение}

Очевидно, что точность прогнозов, равно как и популярность (а, следовательно, и доходность) данного вида сервиса существенно зависит от числа участников ролевых игр, рассмотренного выше типа, в том числе, числа преподавателей, формирующих дополнительные экспертные суждения. Именно поэтому здесь существует вполне определенный потенциал для сотрудничества между университетами различных стран ЕАЭС, например, между университетами Республики Кыргызстан и Республики Казахстан.

\section{ИСПОЛЬЗОВАННАЯ ЛИТЕРАТУРА}

[1] Грудзинский А. О., Бедный А.Б. Трансфер знаний функция инновационного университета // Высшее образование в России. - 2009. - №. 9.

[2] Калиновская Т. Г., Косолапова С. А., Прошкин А. В. Треугольник знаний как фактор инновационного развития //Современные наукоемкие технологии. - 2010. - №. 10. - C. $118-120$.

[3] Кочеткова Т. О., Носков М. В., Шеринева В. А. Университеты Германии: от реформы Гумбольдта до Болонского процесса //Высшее образование в России. $2011-$ №. 3.

[4] Сулейменов И.Э., Габриелян О.А., Седлакова 3.3., Мун Г.А. История и философия науки. - Алматьл: Изд-во КазНУ, - 2018. - 406 с.

[5] Шипилов А. В. Зарплата российского профессора в ее настоящем, прошлом и будущем // ALMA MATER. Вестник высшей школьл. - 2003. - №. 4. - С. 33 - 42. 
[6] Сулейменов И.Э., Габриелян О.А., Мун Г.А. и др. Некоторые вопросы современной теории инноваций. Алмать -Симферополь, 2016, 217 c.

[7] Сулейменов И.Э., Витулёва Е.С. К вопросу о новой парадигме высшего образования // Известия научно-технического общества «КАХАК», 2018, № 3 (62) C. 87-95.

[8] Сулейменов И.Э., Габриелян О.А. Роль философии науки в новой парадигме высшего образования // Вестник АУЭС, 2018. Спец. Выпуск, С. 13-23.

[9] Сулейменов И.Э. Витулёва Е.С. К вопросу о принц̧ипах функичонирования цчентров компетенций // Вестник АУЭС, 2018, №4 (43) С. 142-151

[10] Сулейменов И.Э., Мун Г.А., Кабдушев Ш.Б., Байпакбаева С.Т., Витулёва E.C., Евстифеев В.Н. Деловые экосистемы как фактор стимулирования инновационной активности в Республике Казахстан // Известия научно-технического общества «КАXАК», 2018, № 3 (62), C. 5-18.

[11] Организация и планирование научных исследований / И. Сулейменов, О. Габриелян, В. Буряк, Н. Сафонова, Г. Ирмухаметова, Ш. Кабдушев, Г. Мун. Алматы, Изд-во КазНУ, 2018, 336 с.

[12] Третьяк В. П. Форсайт как технология предвидения //Экономические cтратегии. - 2009. - T. 11. - №. 8. - C. 52-63.

[13] Болотова А.А., Карпунина Е.К. Роль и место маркетинговой стратегии продвижения товара в системе развития современного предприятия //Социальноэкономические явления и процессы. - 2013. - №. 4 (050).

[14] Навроцкая Т.Г., Козловский А.В. Значение рыночных исследований в повышении конкурентных преимуществ организаций на рынке товаров и услуг //Проблемы современной экономики. - 2014. - №. 4 (52).

[15] Янгиров И.И., Зотова Т.В., Саубанова Е.А. Об оценке предпочтений потенциального потребителя банковских услуг на рынке сбережений //Деньги и кредит. - 2007. - №. 3. - C. 31-36.

[16] Крюкова Е.В., Беркетова Л.В., Беленко Е.Л. Разработка новых пищевых продуктов с учетом требований потребителей // Пищевая промышленность. - 2010. - № 8 . 